\title{
The Neural Mechanism of Insight in Children and Adults: An ERPs Study of Chinese-Generation Task
}

\author{
Xiaojuan Jia ${ }^{1,2^{*}}$, Weiping Hu${ }^{2 *}$, Haijun Duan², Senqing $\mathbf{Q i}^{2}$, Xuewei Wang2, Yangping $\mathrm{Li}^{2}$ \\ ${ }^{1}$ West China Higher Education Evaluation Center \& Institute of Higher Education, Xi'an Jiaotong University, Xi'an, China \\ ${ }^{2}$ MOE Key Laboratory of Modern Teaching Technology, Shaanxi Normal University, Xi'an, China \\ Email: ^xiaojuanjia2017@xjtu.edu.cn, *weipinghu@163.com
}

How to cite this paper: Jia, X. J., Hu, W. P., Duan, H. J., Qi, S. Q., Wang, X. W., \& Li, Y. P. (2019). The Neural Mechanism of Insight in Children and Adults: An ERPs Study of Chinese-Generation Task. Psychology, 10, 1856-1867.

https://doi.org/10.4236/psych.2019.1013120

Received: September 2, 2019

Accepted: October 28, 2019

Published: October 31, 2019

Copyright () 2019 by author(s) and Scientific Research Publishing Inc. This work is licensed under the Creative Commons Attribution International License (CC BY 4.0).

http://creativecommons.org/licenses/by/4.0/

(c) (i) Open Access

\begin{abstract}
Insight is not only an important component of creativity, but also a vital way of innovation. The age of $9-10$ is a critical period of the development of creativity; the researches on neural mechanism of children's insight are useful to the understanding of human creativity development process. Development differences in the time course of brain activations involved in conflict processing of insight were examined for 19 children aged 9 - 10 and 15 young adults when they performed the Chinese character-generation task by adding one stroke (Qiu et al., 2007; Zhao et al., 2011). Results showed that: 1) Aha answers elicited a more negative ERP deflection (N300 - 400) than did Noaha answers in the time window from $300-400 \mathrm{~ms}$ after onset of the answer; but there was no significant difference between children and adults, which indicated that the cognitive conflict processing between old and new ways of thinking while identifying the answers was similar between children and adults. 2) Aha answers elicited a late positive component (LPC) than did No-aha answers in the time window from 500 - 1000 ms. More importantly, in the Aha condition, LPC had greater amplitude in children than adults; while in No-aha condition, there was no significant difference between two groups, which suggested that in the cognitive processes of updating and maintaining the correct information in the working memory, children need more attentional resources than adults.
\end{abstract}

\section{Keywords}

Insight, Creativity, ERPs (Event-Related Potentials)

\section{Introduction}

Insight is not only an important component/stage of creativity, but also a vital 
way of innovation. Insight is defined as "any sudden comprehension, realization, or problem solution that involves a reorganization of the elements of a person's mental representation of a stimulus, situation, or event to yield a nonobvious or nondominant interpretation" (Kounios \& Beeman, 2014). During the last century, researches on insight mainly focus on cognitive behavior studies using classic insight problems, such as the Nine-Dot Problem, the Candle Problem, the Double Line Problem (Dow \& Mayer, 2004; Gilhooly \& Murphy, 2005) and so on. However, the neural basis of insight remains unknown.

Developed cognitive neuroscience techniques such as event-related potentials (ERPs) have made it possible to record the time course of brain activity associated with insight problem solving. For example, using ERPs time-locked to the riddle solution word's presentation, Mai, Luo, Wu, \& Luo (2004) found a greater negativity (N380) in the time window of $250-500 \mathrm{~ms}$ for the Aha answer than No-aha answer, which probably reflected an "Aha" effect, and maybe involved in the breaking mental set. When the Chinese logogriph answers were provided, Qiu et al. (2006) found both the Aha and Uncomprehended answers elicited a negative component (N320) than No-aha answer, which might reflect the cognitive conflict. Similarly, other researchers also found the negative component which reflected the cognitive conflict. Such as, using the Chinese character-generation task, Qiu et al. (2007) observed a more negative ERP deflection (N320) for Unexpected Correct and Incorrect answers than Consistent answers. With ERP time-locked to the Chinese logogriph task presentation, Wang et al. (2009) observed a N300 - 800 for successful insight solving than routine problem solving. Adopting the Chinese logogriph solution's presentation, Xing, Zhang, \& Zhang (2012) found a N300 - 500 for insight trials than non-insight trials. Likewise, some researchers also found the similar ERPs negativity which reflected the breaking mental set. For example, using a learning-testing experimental paradigm with time-locked to the target logogriph's presentation, Luo et al. (2011) found a N300 - 500 for structural similarity logogriphs than surface similarity logogriphs. Shen et al. (2013) controlled the effects of variable working memory load with the length of each logogriph was three Chinese characters and each possible solution including only of one, finding both insightful solution and incomprehension solutions elicited a more negativity (N320 - 550) than non-insightful solutions.

Meanwhile, in the later time window, researchers found some late ERP components which reflected the formation of novel association (Luo et al., 2011; Qiu et al., 2007; Qiu et al., 2008; Xing et al., 2012; Zhang, Tian, Wu, Liao, \& Qiu, 2011; Zhang et al., 2015; Zhao et al., 2011). For example, adopting Chinese character-generation task, anagram, or Chinese logogriph separately, Qiu et al. (2007), Zhang et al. (2011) and Zhang et al. (2015) found that insight solutions elicited a more positive ERP deflection (LPC) than non-insight solutions in the time window of $500-600 \mathrm{~ms}, 640-780 \mathrm{~ms}$, or 400 - $600 \mathrm{~ms}$ separately. Using a learning-testing experimental paradigm, Zhao et al. (2011) observed breaking 
mental set method elicited a more positive component (P900 - 1300) than a fixed way-repeated method, and Luo et al. (2011) found both surface similarity logogriphs and structural similarity logogriph demonstrated a greater positivity (P900 - 1700) than the base logogriphs, while Qiu et al. (2008) found a negativity (N1500 - 2000) which is different from majority of studies for successful guessed logogriphs than unsuccessful logogriphs in a much more later time window. With time-locked to the logogriph solution's presentation, Xing et al. (2012) observed a P600 - 1100 for insight condition than non-insight condition.

Of greater importance and interest, these different studies, with different materials and different test procedures, which used adults as participants all pointed out two similarly key cognitive processes-breaking mental set/cognitive conflict and formation of novel association-during insight problem solving. That is, in the process of solving insight problem, an ERP component (N380, N320, N320 550 , or N300 - 500) would be elicited in the time window of about $300-500 \mathrm{~ms}$, which may reflect breaking mental set or cognitive conflict; later another ERP component (LPC, P600 - 1100, P900 - 1300, P900 - 1700, or N1500 - 2000) would be observed in the time window of after $600 \mathrm{~ms}$, which may be related to the formation of novel association.

The age of 9 - 10 who are at fourth grade of primary school is a critical and increasing period of the development of creativity (Camp, 1994; Charles \& Runco, 2001; Maker, Jo, \& Muammar, 2008; Mullineaux \& Dilalla, 2009; Smith \& Carlsson, 1983); and the researches on neural mechanism of children's insight are useful to the understanding of human creativity development process. However, less attention on children's neural mechanism of insight, though there are a large number of empirical researches on adult insight problem solving. In the present study, development differences in the time course of brain activations involved in conflict and forming novel association processing of insight were examined for 9 - 10 years old children, compared with young adults when they performed the Chinese character-generation task by adding one stroke (Qiu et al., 2007; Zhao et al., 2011).

\section{Methods}

\subsection{Participants}

Thirty-four subjects participated in this study: 19 children of 9 - 10 years old (9 female, mean age $9.91 \pm .34$ ), and 15 young adults of 18 - 26 years old ( 7 female, mean age $21.50 \pm 2.63$ ). The parents of the children and the young adults were informed about the general characteristics of the experiment and gave written informed consent prior to the start of the study. All participates were righthanded, had no history of current or past neurological or psychiatric illness, and had normal or corrected-to-normal vision.

\subsection{Stimuli}

Stimuli were 164 familiar Chinese characters selected from The Contemporary 
Chinese Dictionary (see Qiu et al., 2007; Zhao et al., 2011).

82 characters could be transformed into only one other character by adding one stroke (e.g., 一, I, 、, J). For example, 休 can be changed into 体 by adding the horizontal stroke “一”; 旦 can be changed into 早 by adding the vertical stroke "I"; 厂 can be changed into 广 by adding the point stroke “、”; 代 can be changed into 伐 by adding the skimming stroke “ J".

All Chinese characters were composed of 3 - 10 strokes and were randomly displayed in the center of a 19 -inch screen at a font size of 25 , using the font face Song (for example 休 and 体).

\subsection{Procedure}

Each trial of the character-generation task was as follows (In detail, the sequence of events was as follows, see Figure 1). First, a fixation point appeared for 800 ms in the center of the screen and was followed by a Chinese character and question mark simultaneously for $3500 \mathrm{~ms}$. Participants were instructed to decide whether the character could be formed into a new character by adding one stroke, and to press " $\mathrm{z}$ " key with their left index finger if they could actually generate it. Next, after a random 800 - $1000 \mathrm{~ms}$ interval, a correct answer was presented for $5000 \mathrm{~ms}$. Participants were asked to decide whether the given character was same with the character they thought out just now. Press the "1" key with the right index finger if their thought answer was the same as the character displayed on the screen or press the "2" key with the right middle finger if they didn't thought out the correct answer, but they could understand the answer displayed on the screen. Then there was a $1000 \mathrm{~ms}$ interval. The number keys "1" and " 2 " were balanced across subjects.

The whole test was divided into three parts for the children. First, named interpretation part, explain how to do the task, and guide the children to do it with 2 trials. Second, to familiarize the children with the procedure and pace of the task independently, they practiced 4 items using the same procedure, before the formal experiment. Then, the formal ERP experiment started. There are 2 blocks and each one had 38 trials with randomly displaying. Between blocks, participants could take a rest. For the adults, there were only two parts, practice and the formal experiment. Participants were seated in a quiet room facing a screen placed at approximately $80 \mathrm{~cm}$ distance from the eyes and were instructed to respond as fast and accurately as possible by pressing the corresponding key. Participants were asked to try to make as few movements and to limit eye blinks.

Once the participants finished the whole task, we used the subjective reports on the experience. Specifically, each participant reported his or her experience when they saw the standard answer after finishing the whole task. Results showed that they generally reported an "Aha" feeling when they saw the standard answer if their answer was incongruent with the standard answer or they did not think out the correct answer but could understand it. Conversely, there was no "Aha" feeling if their answer was the same with the standard answer. 


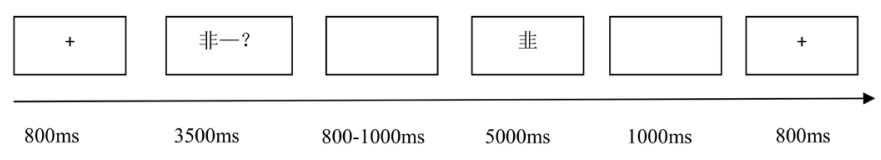

Figure 1. Sequence of events for each trial.

\subsection{EEG Recording and Data Analysis}

The electroencephalogram (EEG) was recorded continuously from 64 scalp cites according to the international $10-20$ system, using the Curry 7 System with the reference on the left mastoid and rereferenced offline to the average activity at left and right mastoids. Eye movement artifacts and blinks were monitored via horizontal electrooculogram (HEOG) placed at the outer canthi of each eye and vertical electrooculogram (VEOG) placed above and below the left eye. All interelectrode impedance was below $5 \mathrm{k} \Omega$. All EEG signals were digitized with a sample frequency of $1000 \mathrm{~Hz}$ and were online band-pass filtered from DC to $100 \mathrm{~Hz}$.

The ERP processing was conducted offline using EEGLAB and ERPLAB4.0 (Lopez-Calderon \& Luck, 2014) software. Offline, the EEG recording was resampled at a $500 \mathrm{~Hz}$ channel, and digitally filtered with a $.05-30 \mathrm{~Hz}$ band-pass filter. Eye movement artifacts (blinks and eye movements) were rejected by using Independent Component Analysis method (ICA). According to participants' responses (decide whether the given character was same with the character they thought), EEG of Congruent and Incongruent overlapped. EEG epochs were generated from $-200 \mathrm{~ms}$ to $1000 \mathrm{~ms}$ relative to the standard answer onset, with a $200 \mathrm{~ms}$ pre-stimulus baseline correction, and were excluded from averaging automatically if they contained activity exceeding $\pm 100 \mu \mathrm{V}$ at any site. At least 30 trials were available for each subject and condition.

Based on inspection of the ERPs grand-averaged waveforms and previous researches (Luo et al., 2011; Zhao et al., 2011), mean N300 - 400 amplitudes were evaluated in the following 9 electrode points $(\mathrm{C} 1, \mathrm{Cz}, \mathrm{C} 2, \mathrm{CP} 1, \mathrm{CPz}, \mathrm{CP} 2, \mathrm{P} 1, \mathrm{Pz}$, and P2), and analyzed by using 2 (Age Group: Children, Adults) ${ }^{*} 2$ (Answer Type: Congruence, Incongruence) repeated measure ANOVA.

Mean LPC amplitudes were evaluated as the average activity in three regions/hemispheres: left hemisphere (CP3, CP5, P3, P5, and PO3), central $(\mathrm{CPz}$, $\mathrm{Pz}$, and $\mathrm{POz}$ ), and right hemisphere (CP4, CP6, P4, P6, and PO4); and calculated separately for three time windows: $500-600 \mathrm{~ms}, 600-800 \mathrm{~ms}, 800-1000 \mathrm{~ms}$. Analyses were conducted using 2 (Age Group: Children, Adults) * 2 (Answer Type: Congruent, Incongruent) $* 3$ (Hemisphere: Left, Central, Right) repeated measure ANOVA. The Greenhouse-Geisser correction was applied to the $\mathrm{p}$-values associated with multiple $\mathrm{df}$ comparisons when tests violated assumptions of sphericity.

\section{Results}

\subsection{Behavioral Data}

Both numbers and Reaction times (RTs) in congruent and incongruent trials were analyzed using a 2 Age Group (Children, Adults) * 2 Answer Type (Con- 
gruence, Incongruence) mixed-design ANOVA with age group as the betweensubject factor and answer type as within-subject factor. As to the trails on different conditions of answer type, the main effect of answer type was significant, $F_{(1,32)}=27.17, p<.001$, partial $\eta^{2}=.492$; compared with the incongruence condition, there were more trials on congruent condition (see Table 1 and Figure 2). As to RTs on different conditions of answer type, there was a main effect of answer type, $F_{(1,32)}=150.57, p<.001$, partial $\eta^{2}=.834$ and main effect of age group, $\left.F_{(1,32}\right)=21.92, p<.001$, partial $\eta^{2}=.422$; RTs for incongruent condition were significantly slower than RTs for congruent condition; children's RTs were significantly longer than those of young adults (see Table 1 and Figure 2).

\subsection{Event-Related Potentials (ERPs) Data}

\section{N300 - 400 component}

$300-400 \mathrm{~ms}$

Figure 3 showed that incongruence elicited a more negative deflection than did congruence in the time window $300-400$ ms. The mean amplitude of N300 400 was submitted to a 2 Age Group (Children, Adults) * 2 Answer Type (Congruence, Incongruence) repeated measures ANOVA. Results showed that there was a significant main effect of answer type, $F_{(1,32)}=10.92, p=.003$, partial $\eta^{2}=$.332; Post-hoc contrasts, Bonferroni corrected for multiple comparisons, indicated that mean amplitude was more negative for the incongruent condition $(2.47 \pm 7.10 \mu \mathrm{V})$ than for the congruent condition $(7.17 \pm 6.38 \mu \mathrm{V})$. The main effect of age group and the interaction effect between the age group and answer type were not significant.

\section{LPC component}

$500-1000 \mathrm{~ms}$

After the negative component, a late positive component (LPC) was elicited by the two conditions within the time window $500-1000 \mathrm{~ms}$, which were calculated separately for three time windows: $500-600 \mathrm{~ms}, 600-800 \mathrm{~ms}, 800-1000$ ms (see Figure 4), using a 2 Age Group (Children, Adults)* 2 Answer Type (Congruence, Incongruence) * 3 Hemisphere (Left, Central, Right) repeated measure ANOVA.

In the time window $500-600 \mathrm{~ms}$, the main effect of answer type was significant, $F_{(1,32)}=7.06, p=.014$, partial $\eta^{2}=.243$; Post-hoc contrasts, Bonferroni corrected for multiple comparisons, indicated that the incongruent condition $(9.46 \pm 5.58$ $\mu \mathrm{V})$ showed a higher voltage than the congruent condition $(6.75 \pm 4.16 \mu \mathrm{V})$.

Table 1. Mean numbers and Reaction times under congruent and incongruent trials in children and young adults.

\begin{tabular}{ccccc}
\hline & \multicolumn{2}{c}{ Number of trials } & \multicolumn{2}{c}{ Reaction times } \\
\hline Answer type & $\begin{array}{c}\text { Congruence } \\
(M \pm S D)\end{array}$ & $\begin{array}{c}\text { Incongruence } \\
(M \pm S D)\end{array}$ & $\begin{array}{c}\text { Congruence } \\
(M \pm S D)\end{array}$ & $\begin{array}{c}\text { Incongruence } \\
(M \pm S D)\end{array}$ \\
\hline Children & $46 \pm 14$ & $31 \pm 11$ & $907 \pm 170$ & $1526 \pm 328$ \\
Adults & $49 \pm 7$ & $29 \pm 7$ & $660 \pm 122$ & $1153 \pm 220$ \\
\hline
\end{tabular}




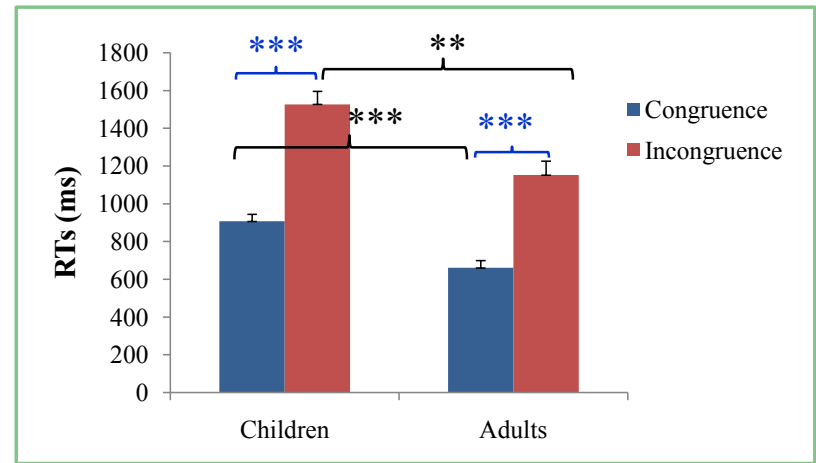

Figure 2. Reaction times on different conditions of answer type and age group. Error bars represent standard errors of the mean. ${ }^{\star *} p<.001 ;{ }^{\star *} p<.01$.

\section{Children}
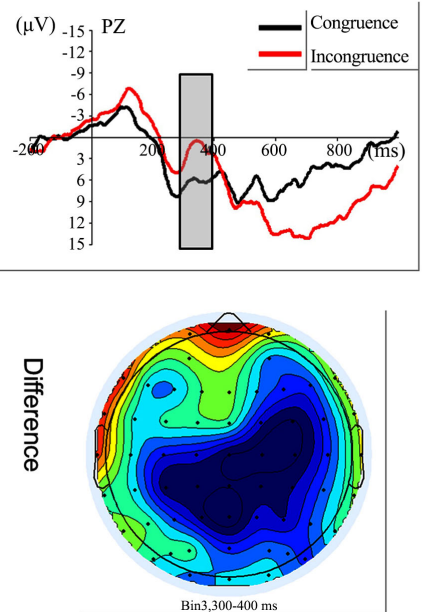

\section{Young Adults}
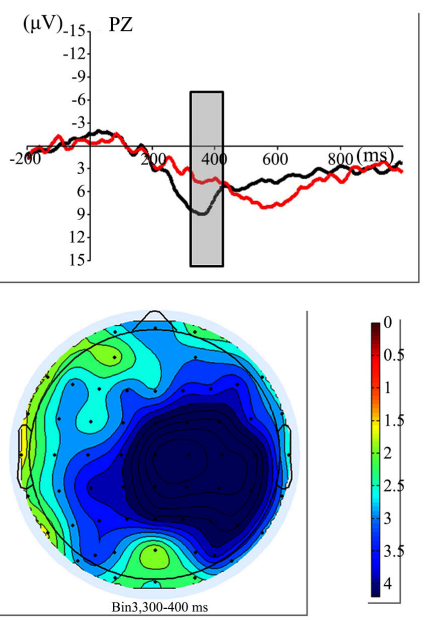

Figure 3. Grand average ERPs, topographical maps of the voltage amplitudes for incongruent vs. congruent condition difference wave at the $300-400 \mathrm{~ms}$ for children and young adults. The gray bars illustrate the time window where the mean amplitude was calculated. Note: The Y-axis is negative up and positive down.
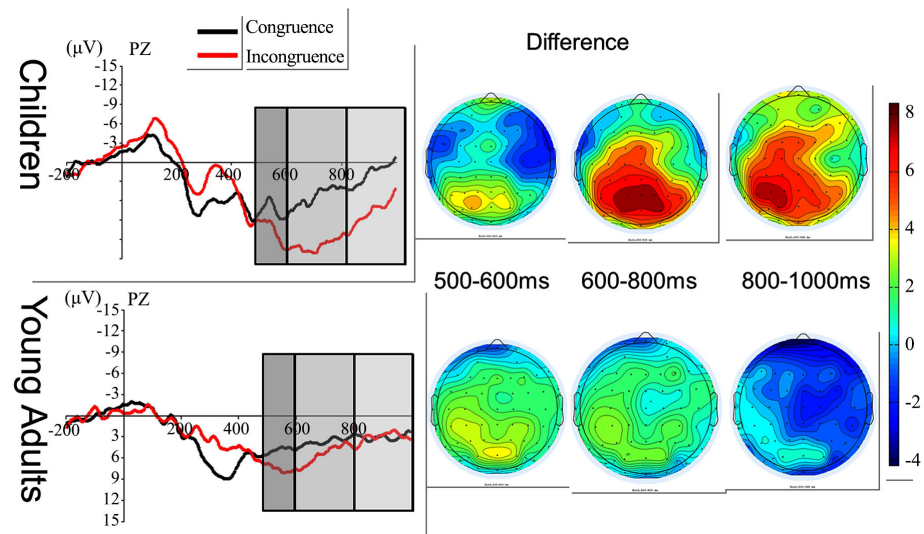

Figure 4. Grand average ERPs, topographical maps of the voltage amplitudes for incongruent vs. congruent condition difference wave at the $500-600 \mathrm{~ms}, 600-800 \mathrm{~ms}, 800-$ $1000 \mathrm{~ms}$ for children and young adults. The gray bars illustrate the time window where the mean amplitude was calculated. Note: The Y-axis is negative up and positive down. 
In the time window $600-800 \mathrm{~ms}$, there was a significant main effect of age group, $F_{(1,32)}=7.06, p=.014$, partial $\eta^{2}=.243$, significant main effect of answer type, $F_{(1,32)}=21.88, p<.001$, partial $\eta^{2}=.499$, as well as a significant interaction effect between age group and answer type, $F_{(1,32)}=7.30, p=.013$, partial $\eta^{2}$ $=.249$. Further analysis showed that, in the incongruent condition, simple effect of age group was significant $\left(F_{(1,32)}=10.23, p=.004\right.$, partial $\left.\eta^{2}=.317\right)$, LPC had greater amplitude in children $(13.03 \pm 5.52 \mu \mathrm{V})$ than adults $(5.79 \pm 5.54 \mu \mathrm{V})$; while in congruent condition, simple effect of age group was not significant $\left(F_{(1,32)}=1.93, p=.178\right.$, partial $\left.\eta^{2}=.081\right)$, that is there was no significant difference between the two age groups (see Figure 5).

In the time window $800-1000 \mathrm{~ms}$, there was a significant main effect of answer type, $F_{(1,32)}=10.92, p=.003$, partial $\eta^{2}=.332$, as well as a significant interaction effect between age group and answer type, $F_{(1,32)}=13.46, p=.001$, partial $\eta^{2}=.380$; the main effect of age group was not significant. Further analysis showed that, in the incongruent condition, simple effect of age group was significant $\left(F_{(1,32)}=6.78, p=.016\right.$, partial $\left.\eta^{2}=.236\right)$, LPC had greater amplitude in children $(9.21 \pm 5.66 \mu \mathrm{V})$ than adults $(3.19 \pm 5.64 \mu \mathrm{V})$; while in congruent condition, simple effect of age group was not significant $\left(F_{(1,32)}=.01, p=.912\right.$, partial $\left.\eta^{2}=.001\right)$, that is there was no significant difference between the two age groups (see Figure 6).

\section{Discussion}

The main goal of the current study was to characterize the time course of brain activations associated with children's and young adults' processing of insight problem solving. The behavioral results showed that children's RTs were significantly longer than those of young adults; the ERP results indicated that both children and adults showed a greater negativity (N300 - 400) in the Incongruent (Aha) condition than the Congruent (No-aha) condition without significant differences between the two groups, while children showed greater LPC amplitude

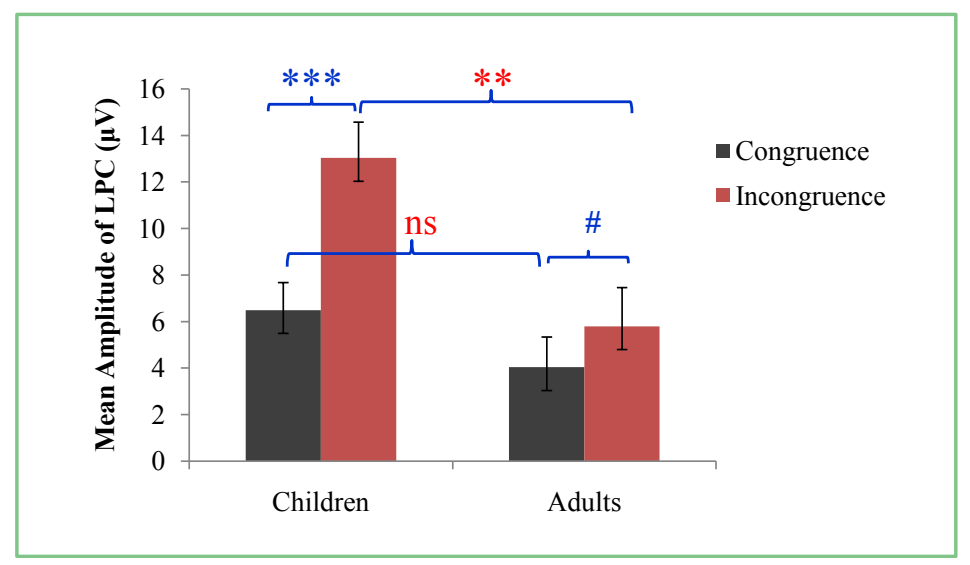

Figure 5. Mean amplitude of LPC on different conditions of answer type and age group in the time window $600-800 \mathrm{~ms}$. Error bars represent standard errors of the mean. ${ }^{* *} p$ $<.001,{ }^{* *} p<.01$, \#represents marginal significance, ns represents no significant. 


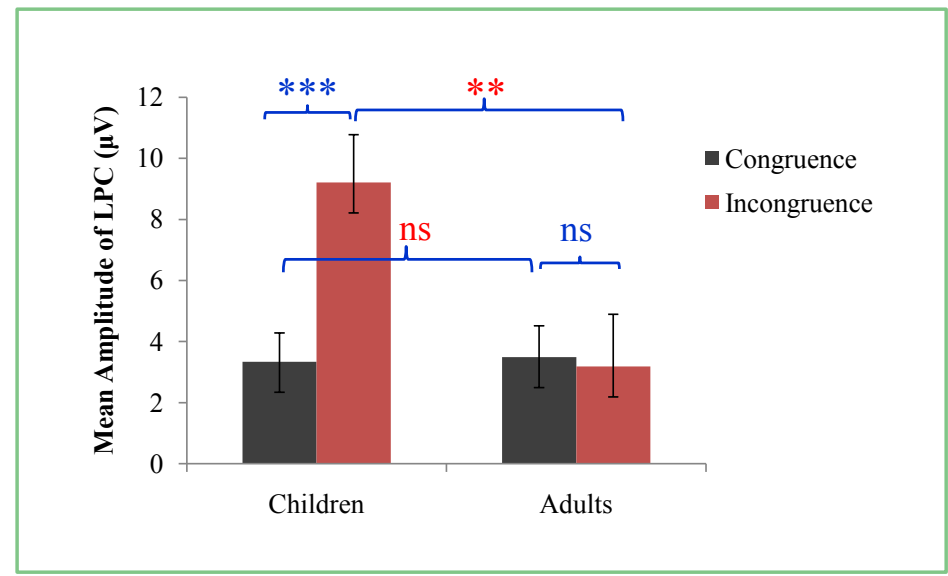

Figure 6. Mean amplitude of LPC on different conditions of answer type and age group in the time window $800-1000 \mathrm{~ms}$. Error bars represent standard errors of the mean. ${ }^{\star *} p$ $<.001 ;{ }^{* *} p<.01$.

in the Incongruent condition than adults. These results suggested that the cognitive conflict processing is similar between children and adults, but children need more attentional resources than adults in the later processes of updating and maintaining the correct information.

\section{N300 - 400 component (Time course of cognitive conflict)}

Incongruent (Aha) answers elicited a more negative ERP deflection (N300 400) than did Congruent (No-aha) answers in the time window of $300-400 \mathrm{~ms}$ after onset of the answer, which is similar to the N380 (Mai et al., 2004), the N320 (Qiu et al., 2006, 2007) and the N300 - 500 (Xing et al., 2012). In the Chinese character-generation task presented herein, participants tried their best to answer the question, so a thought process formed in the initial stage of generating a new character (the old thought). Regardless of whether or not they could resolve the task, when a possible answer was presented, participants identified and judged the character using new thought processes when the answer was not the same as the one they had generated. Evidently, they would experience transition from the old thought to a new thought, inducing cognitive conflict (Qiu et al., 2007). Further, results suggested that both in children and adults showed a N300 - 400 without significant difference, which indicated that the cognitive conflict processing between old and new ways of thinking while identifying the answers was similar between children and adults.

\section{LPC component (Time course of formation novel association)}

Incongruent (Aha) answers elicited a late positive component (LPC) than did Congruent (No-aha) answers in the time window of $500-1000 \mathrm{~ms}$, consisted with the LPC or slow wave components observed in previous researches (Luo et al., 2011; Qiu, et al., 2007, 2008; Xing et al., 2012; Zhang et al., 2011; Zhang et al., 2015; Zhao et al., 2011), which might reflect the processing of formation novel association. The LPC might be P300, shared many similarities and were considered related (Hajcak, Moser, \& Simons, 2006; Huang \& Luo, 2009). LPC was found to be involved in attentional and orienting processes (Knight; 1996; Haj- 
cak, Moser, \& Simons, 2006), with its amplitude reflecting the amount of mental resources employed (Olofsson, Nordin, Sequeira, \& Polich, 2008). P300 was linked to memory updating, encoding, or retrieval, and the formation of new representations through integration (Donchin, 1981), with its amplitude reflecting deployment of attentional resources (Donchin \& Coles, 1988). We suggest that, there was cognitive conflict between the old thought and new thought under the incongruent condition when the answers appeared, shown in the N300 400 effect. To correctly understand the answers, individuals needed to retrieve information related to the answer, confirm and maintain the correct information. Thus, the LPC effect might reflect the processing of updating and maintaining the correct information following the cognitive conflict.

More importantly, in the Aha condition, LPC had greater amplitude in children than adults; while in No-aha condition, there was no significant difference between two groups. This result suggests that in the cognitive processes of updating and maintaining the correct information in the working memory, children need more attentional resources than adults.

\section{Conclusion}

Incongruent (Aha) answers elicited a more negative ERP deflection (N300 - 400) than did Congruent (No-aha) answers in the time window of $300-400 \mathrm{~ms}$ after onset of the answer; but there was no significant difference between children and adults, which indicates that the cognitive conflict processing between old and new ways of thinking while identifying the answers is similar between children and adults.

Incongruent (Aha) answers elicited a late positive component (LPC) than did Congruent (No-aha) answers in the time window of 500 - $1000 \mathrm{~ms}$. More importantly, in the Aha condition, LPC had greater amplitude in children than adults; while in No-aha condition, there was no significant difference between two groups, which suggests that in the cognitive processes of updating and maintaining the correct information in the working memory, children need more attentional resources than adults.

\section{Funding}

This research was supported by Open Funding Project of the Key Laboratory of Modern Teaching Technology, MOE of PRC (SYSK201801), and National Natural Science Foundation of China (31271110, 31470977).

\section{Conflicts of Interest}

The authors declare no conflicts of interest regarding the publication of this paper.

\section{References}

Camp, G. C. (1994). A Longitudinal Study of Correlates of Creativity. Creativity Research 
Journal, 7, 125-144. https://doi.org/10.1080/10400419409534519

Charles, R. E., \& Runco, M. A. (2001). Developmental Trends in the Evaluative and Divergent Thinking of Children. Creativity Research Journal, 13, 417-437. https://doi.org/10.1207/S15326934CRJ1334_19

Donchin, E. (1981). Surprise! Surprise? Psychophysiology, 18, 493-513. https://doi.org/10.1111/j.1469-8986.1981.tb01815.x

Donchin, E., \& Coles, M. G. H. (1988). Is the P300 Component a Manifestation of Context Updating? Behavioral Brain Science, 11, 355-372. https://doi.org/10.1017/S0140525X00058027

Dow, G. T., \& Mayer, R. E. (2004). Teaching Students to Solve Insight Problems: Evidence for Domain Specificity in Creativity Training. Creativity Research Journal, 16, 389-398. https://doi.org/10.1080/10400410409534550

Gilhooly, K. J., \& Murphy, P. (2005). Differentiating Insight from Non-Insight Problems. Thinking \& Reasoning, 11, 279-302. https://doi.org/10.1080/13546780442000187

Hajcak, G., Moser, J. S., \& Simons, R. F. (2006). Attending to Affect: Appraisal Strategies Modulate the Electrocortical Response to Arousing Pictures. Emotion, 6, 517-522. https://doi.org/10.1037/1528-3542.6.3.517

Huang, Y. X., \& Luo, Y. J. (2009). Can Negative Stimuli Always Have the Processing Superiority? An ERP Study. Acta Psychologica Sinica, 41, 822-831. https://doi.org/10.3724/SP.J.1041.2009.00822

Knight, R. T. (1996). Contribution of Human Hippocampal Region to Novelty Detection. Nature, 383, 256-259. https://doi.org/10.1038/383256a0

Kounios, J., \& Beeman, M. (2014). The Cognitive Neuroscience of Insight. Annual Review of Psychology, 65, 71-93. https://doi.org/10.1146/annurev-psych-010213-115154

Lopez-Calderon, J., \& Luck, S. J. (2014). ERPLAB: An Open-Source Toolbox for the Analysis of Event-Related Potentials. Frontiers in Human Neuroscience, 8, 213. https://doi.org/10.3389/fnhum.2014.00213

Luo, J., Li, W., Fink, A., Jia, L., Xiao, X., Qiu, J., \& Zhang, Q. (2011). The Time Course of Breaking Mental Sets and Forming Novel Associations in Insight-Like Problem Solving: An ERP Investigation. Experimental Brain Research, 212, 583-591. https://doi.org/10.1007/s00221-011-2761-5

Mai, X., Luo, J., Wu, J., \& Luo, Y. (2004). “Aha!” Effects in a Guessing Riddle Task: An Event-Related Potential Study. Human Brain Mapping, 22, 261-270. https://doi.org/10.1002/hbm.20030

Maker, C. J., Jo, S., \& Muammar, O. M. (2008). Development of Creativity: The Influence of Varying Levels of Implementation of the Discover Curriculum Model, a Non-Traditional Pedagogical Approach. Learning and Individual Differences, 18, 402-417. https://doi.org/10.1016/j.lindif.2008.03.003

Mullineaux, P. Y., \& Dilalla, L. F. (2009). Preschool Pretend Play Behaviors and Early Adolescent Creativity. The Journal of Creative Behavior, 43, 41-57. https://doi.org/10.1002/j.2162-6057.2009.tb01305.x

Olofsson, J. K., Nordin, S., Sequeira, H., \& Polich, J. (2008). Affective Picture Processing: An Integrative Review of ERP Findings. Biological Psychology, 77, 247-265. https://doi.org/10.1016/j.biopsycho.2007.11.006

Qiu, J., Li, H., Luo, Y., Chen, A. T., Zhang, F., Zhang, J. et al. (2006). Brain Mechanism of Cognitive Conflict in a Guessing Chinese Logogriph Task. NeuroReport, 17, 679-682. https://doi.org/10.1097/00001756-200604240-00025

Qiu, J., Li, H., Yang, D., Luo, Y., Li, Y., Wu, Z., \& Zhang, Q. (2008). The Neural Basis of 
Insight Problem Solving: An Event-Related Potential Study. Brain and Cognition, 68, 100-106. https://doi.org/10.1016/j.bandc.2008.03.004

Qiu, J., Zhang, Q., Li, H., Luo, Y., Yin, Q., Chen, A., \& Yuan, H. (2007). The Event-Related Potential Effects of Cognitive Conflict in a Chinese Character-Generation Task. Neuroreport, 18, 881-886. https://doi.org/10.1097/WNR.0b013e3280d9e896

Shen, W., Liu, C., Zhang, X., Zhao, X., Zhang, J., Yuan, Y., \& Chen, Y. (2013). Right Hemispheric Dominance of Creative Insight: An Event-Related Potential Study. Creativity Research Journal, 25, 48-58. https://doi.org/10.1080/10400419.2013.752195

Smith, G. J. W., \& Carlsson, I. (1983). Creativity in Early and Middle School Years. International Journal of Behavioral Development, 6, 167-195. https://doi.org/10.1177/016502548300600204

Wang, T., Zhang, Q., Li, H., Qiu, J., Tu, S., \& Yu, C. (2009). The Time Course of Chinese Riddles Solving: Evidence from an ERP Study. Behavioural Brain Research, 199, 278-282. https://doi.org/10.1016/j.bbr.2008.12.002

Xing, Q., Zhang, J. X., \& Zhang, Z. (2012). Event-Related Potential Effects Associated with Insight Problem Solving in a Chinese Logogriph Task. Psychology, 3, 65-69. https://doi.org/10.4236/psych.2012.31011

Zhang, M., Tian, F., Wu, X., Liao, S., \& Qiu, J. (2011). The Neural Correlates of Insight in Chinese Verbal Problems: An Event Related-Potential Study. Brain Research Bulletin, 84, 210-214. https://doi.org/10.1016/j.brainresbull.2011.01.001

Zhang, Z., Xing, Q., Li, H., Warren, C. M., Tang, Z., \& Che, J. (2015). Chunk Decomposition Contributes to Forming New Mental Representations: An ERP Study. Neuroscience Letters, 598, 12-17. https://doi.org/10.1016/j.neulet.2015.05.008

Zhao, Y., Tu, S., Lei, M., Qiu, J., Ybarra, O., \& Zhang, Q. (2011). The Neural Basis of Breaking Mental Set: An Event-Related Potential Study. Experimental Brain Research, 208, 181-187. https://doi.org/10.1007/s00221-010-2468-z 